\title{
The anti-inflammatory effect of milk and dairy products on periodontal cells: an in vitro approach
}

\author{
Layla Panahipour $^{1} \cdot$ Shayesteh Nasserzare ${ }^{1} \cdot$ Zeinab Amer $^{1}$ • Friedrich Brücke ${ }^{1} \cdot$ Alexandra Stähli $^{1,2}$. $^{2}$ \\ Alexandra Kreissl $^{3} \cdot$ Nadja Haiden $^{3} \cdot$ Reinhard Gruber ${ }^{1,2,4}$
}

Received: 28 May 2018 / Accepted: 11 September 2018 / Published online: 20 September 2018

(C) The Author(s) 2018

\begin{abstract}
Objective Milk can reduce intestinal tissue damage in colitis models, and protects infants against necrotizing enterocolitis. However, whether milk can decrease inflammation related to peri-implantitis and oral mucosal dehiscence remains unclear. We therefore investigated whether or not milk and fermented by-products have any anti-inflammatory effects on the cells of the oral cavity.

Material and methods Human gingival fibroblasts and the human oral epithelial cell line HSC2 were exposed to pasteurized human milk, pasteurized cow's milk, dairy products, and powdered milk. An inflammatory response was then provoked with IL1 and TNF $\alpha$. The expression changes of IL1, IL6, and IL8 were detected by reverse transcriptase PCR and immunoassay.

Results We can report that pasteurized human milk and pasteurized cow's milk as well as yoghurt, buttermilk, sour milk, whey, and powdered milk can lower the expression of inflammatory cytokines in gingival fibroblasts being stimulated by IL1 and TNF $\alpha$. A similar anti-inflammatory response to pasteurized milk and dairy products was observed with the human oral epithelial cell line HSC2.

Conclusion These data suggest that pasteurized and powdered milk, as well as fermented dairy products, display an antiinflammatory effect on oral fibroblasts and oral epithelial cells.

Clinical relevance Our in vitro findings provide the scientific basis to extend this research towards testing the anti-inflammatory effects of milk in a pre-clinical periodontitis and peri-implantitis model.
\end{abstract}

Keywords Oral $\cdot$ Mucositis $\cdot$ Milk $\cdot$ Inflammation $\cdot$ Fibroblasts $\cdot$ Epithelial cells

Electronic supplementary material The online version of this article (https://doi.org/10.1007/s00784-018-2642-4) contains supplementary material, which is available to authorized users.

Reinhard Gruber

reinhard.gruber@meduniwien.ac.at

1 Department of Oral Biology, Medical University of Vienna, Sensengasse 2a, 1190 Vienna, Austria

2 Department of Periodontology, School of Dental Medicine, University of Bern, Freiburgstrasse 7, 3010 Bern, Switzerland

3 Department of Paediatrics and Adolescent Medicine, Division of Neonatology, Medical University of Vienna, Währingergürtel 18-20, 1090 Vienna, Austria

4 Austrian Cluster for Tissue Regeneration, Donaueschingenstraße 13, 1200 Vienna, Austria

\section{Introduction}

Milk is produced by the mammary gland, and contains nutritional components for the growth and development of infants. Milk can reduce inflammation of the intestine, for example, necrotizing enterocolitis $[1,2]$. Both human milk and cow's milk lower tissue injury and even mortality in chemically induced endotoxemia models [3]. Further support for the antiinflammatory activity of milk is based on in vitro studies. For example, pre-term human milk suppresses TNF $\alpha$-induced inflammation in intestinal epithelial cells [4], while casein hydrolysate and its peptide-enriched fractions reduce the inflammatory response in Caco-2 cells and porcine colonic explants [5]. Whey protein hydrolysates decrease IL8 secretion in LPS-stimulated respiratory epithelial cells [6]. However, it is 
unknown if the anti-inflammatory effect of milk is independent of the target cells. If this is so, it is reasonable to suggest that milk exerts its anti-inflammatory effect in models representing inflammation of the oral cavity.

Fermentation causes the denaturation of casein, and changes the rheological properties of yoghurt, sour milk, and buttermilk [7]. Pasteurization usually occurs at approximately $72{ }^{\circ} \mathrm{C}$ for $15 \mathrm{~s}$ [8] and for the preparation of yoghurt, milk is heated to $80^{\circ} \mathrm{C}$ to $95^{\circ} \mathrm{C}$ for 10 to $30 \mathrm{~min}[9,10]$. Powdered milk is heated to $160^{\circ} \mathrm{C}$ or higher [11]. On the other hand, for the production of cheese, casein is cleaved by rennet extract, or by enzymes derived from plants, fungi, and microbial sources [12]. What remains from milk after coagulation are the whey serum proteins. Whey attenuates inflammationinduced intestinal injury by improving mucosal barrier function [13]. Yoghurt has an anti-inflammatory activity in humans with inflammatory bowel disease, and in experimentally induced inflammatory bowel disease in mice. [14, 15] Yoghurt can also prevent Candida albicans-induced mucosal inflammation and proliferation in the forestomach of diabetic rats [16]. The question arises as to whether powdered milk and fermented milk products induce an anti-inflammatory response in oral cells?

Gingival fibroblast and oral epithelial cells are suitable to use for in vitro models to study the possible antiinflammatory role of milk and its fermented products $[17,18]$. With this bioassay, these cells were exposed to aqueous fractions of cow's milk and human milk, as well as fermented milk products with and without IL1 and TNF $\alpha$. Usually, the cells responded with an increased production of cytokines including IL1, IL6, and IL8. The question arises as to whether this inflammatory response can be attenuated by aqueous fractions of milk, fermented milk products, and powdered milk. The aim of the present study was to determine the anti-inflammatory role of milk and milk products, with bioassays relevant for oral health, particularly oral mucositis in patients suffering from radiation [19], chemotherapy [20], and chronic inflammatory disorders such as Crohn's disease [21], periodontitis, and peri-implantitis.

\section{Material and methods}

\section{Human milk, cow's milk, fermented milk products, and cells}

Human milk samples were collected at the Department of Paediatrics and Adolescent Medicine, Division of Neonatology, of the Medical University of Vienna. Mother's milk was prepared in daily totals for premature babies and delivered to the feeding stations. Three leftover residual amounts, which had been thawed and could not be refrozen, were used for the present study. No mother donated the milk for the study purpose by primary intension (Ethical Committee of the Medical University of Vienna Nr. 1021/2017). Human milk was centrifuged at $20,000 \mathrm{~g}$ for $10 \mathrm{~min}$ at $4{ }^{\circ} \mathrm{C}$. One aliquot was heated up to $85{ }^{\circ} \mathrm{C}$ for $1 \mathrm{~h}$ before freezing. For cow's milk, three different batches of pasteurized cow's milk (Billa Bergbauern Heumilch; Spar Halbfett Milch; Hofer Milfina Halbfett Milch), yoghurt (Ja Natürlich Naturjoghurt; Clever Joghurt; Nöm Naturjoghurt), sour milk (Hofer Milfina Sauermilch; Nöm Sauermilch; Schärdinger Sauermilch), buttermilk (Ja Natürlich Buttermilch Natur; Clever Buttermilch; Spar free from Buttermilch), and whey (Lattella Naturmolke; Clever Fruchtmolke; Spar free from Molke) were pooled and centrifuged, and then the aqueous fractions were stored at $-20{ }^{\circ} \mathrm{C}$ until testing. For powdered milk, three different batches (Aptamil, Milupa; Babylove, dm; Combiotik, Hipp) were reconstituted and pooled prior to centrifugation. Samples were subjected to not more than two freeze-thaw cycles.

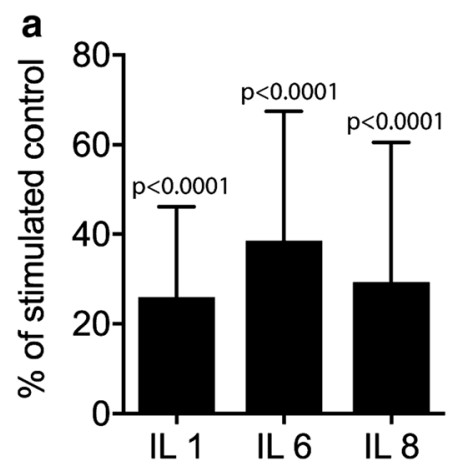

Fig. 1 Human milk and cow's milk suppress induced inflammation in gingival fibroblasts. Gingival fibroblasts were exposed to a fresh-frozen human milk, b pasteurized human milk, and c pasteurized cow's milk
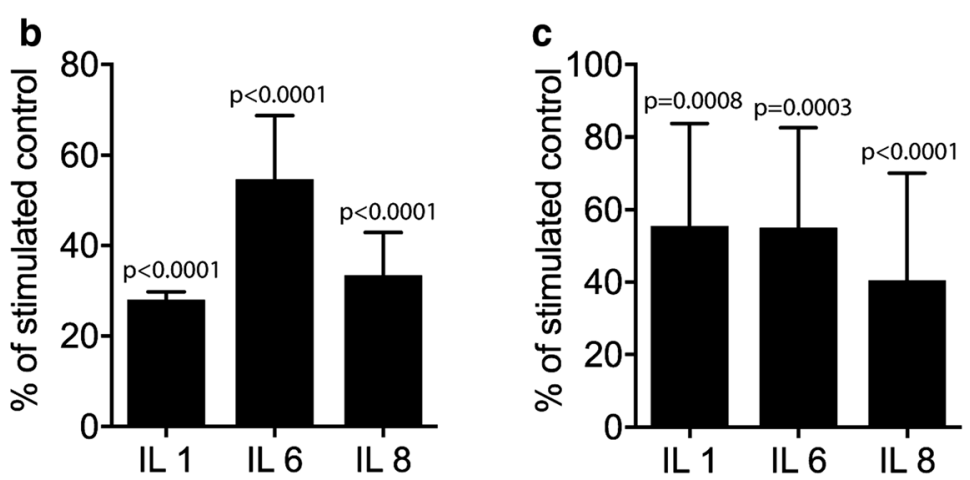

with and without IL-1 and TNF $\alpha$. Data are indicated as a percent of gene expression changes compared to control fibroblasts treated with inflammatory factors. $P$ values are indicated in the graphs 
Table 1 Human milk and cow's milk suppress induced IL6 production in gingival fibroblasts. Gingival fibroblasts were exposed to fresh-frozen human milk, pasteurized human milk, and pasteurized cow's milk with and without IL1 and TNF $\alpha$. $P$ values represent a paired $t$ test compared to the IL1/TNF $\alpha$ group. $M M$ human milk, $H M M$ pasteurized human milk, $C M$ pasteurized cow's milk

\begin{tabular}{llclclrr}
\hline wo & IL1 + TNF & MM & MM + IL1 + TNF & HMM & HMM + IL1 + TNF & CM & CM + IL1 + TNF \\
\hline 8 & 354 & 11 & 144 & 29 & 236 & 30 & 300 \\
3 & 295 & 7 & 206 & 8 & 204 & 4 & 150 \\
2 & 230 & 7 & 93 & 5 & 88 & 3 & 110 \\
& & & $P=0.04$ & & $P=0.11$ & $P=0.19$ \\
\hline
\end{tabular}

\section{Primary gingival fibroblasts and HSC2 cells}

Human gingival fibroblasts were prepared from explant cultures of three independent donors after approval of the Ethical Committee of the Medical University of Vienna (EK Nr. 631/ 2007). The epithelial cell line HSC2 was kindly provided by Prof. Rausch-Fan, Department of Periodontology, Medical University of Vienna, Vienna, Austria. Cells were cultured in a humidified atmosphere at $37{ }^{\circ} \mathrm{C}$ in a growth medium consisting of DMEM, $10 \%$ fetal calf serum, and $1 \%$ antibiotics (Invitrogen Corporation, Carlsbad, CA, USA). Cells were plated in growth medium at 30,000 cells $/ \mathrm{cm}^{2}$ into culture dishes. The following day, cells were exposed to $5 \%$ aqueous fractions of the respective preparations for $1 \mathrm{~h}$ before adding human IL- $1 \beta$ and TNF $\alpha$ (ProSpec-Tany TechnoGene Ltd., Rehovot, Israel), both at $5 \mathrm{ng} / \mathrm{ml}$ in growth medium. After $24 \mathrm{~h}$, gene expression analysis was performed and supernatant was collected for immunoassays.

\section{qRT-PCR analysis and immunoassay}

Total RNA was isolated with the ExtractMe total RNA kit (Blirt S.A., Gdańsk, Poland). Reverse transcription was performed with SensiFAST ${ }^{\mathrm{TM}}$ cDNA (Bioline, London, UK). Polymerase chain reaction was done with the SensiFAST ${ }^{\mathrm{TM}}$ SYBR ROX Kit (Bioline) on a 7500 Real-Time PCR System (both Applied Biosystems, Life Technologies Corporation, Carlsbad, CA). Primer sequences are hIL1_F CTGATGGC
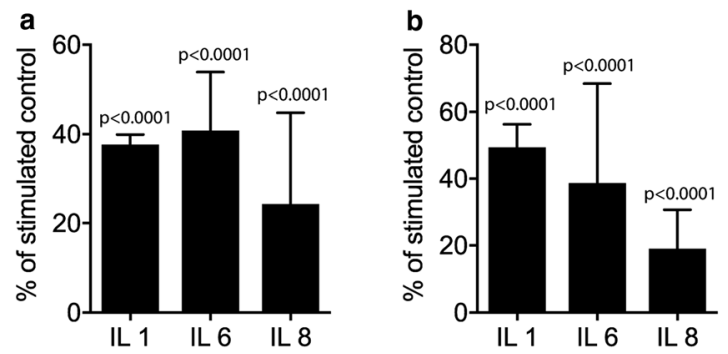

Fig. 2 Fermented milk products reduce IL $1-T N F \alpha$-induced inflammation in gingival fibroblasts. Gingival fibroblasts were exposed to aqueous fractions of a pooled yoghurt, $\mathbf{b}$ sour milk, $\mathbf{c}$ buttermilk, and $\mathbf{d}$
CCTAAACAGATGAAGT, hIL1_R AGCCCTTGCTGTAG TGGTGGT; hIL6_F AATTCGGTACATCCTCGACGG, hIL6_R GGGCATGGATTTCAGACCC; hIL 8_F AACTTCTCCACAACCCTCTG, hIL8 R TTGGCAGC CTTCCTGATTTC; hGAPDH_F AAGCCACATCGCTC AGACAC, hGAPDH_R GCCCAATACGACCAAATCC. The mRNA levels were calculated by normalizing to the housekeeping gene GAPDH using the $\Delta \Delta \mathrm{Ct}$ method after exponential expression transformation. For the immunoassay, the human IL6 and IL8 Quantikine ELISA kit was used (R\&D Systems, Minneapolis, MN).

\section{Statistical analysis}

ANOVA testing comparing the mean rank of each treatment group with the mean rank of the untreated control group, followed by an uncorrected Fischer's LSD post hoc test, was performed. The $P$ values are indicated in the respective figures.

\section{Results}

\section{Human milk and cow's milk suppress induced inflammation in gingival fibroblasts}

The aqueous fractions of fresh-frozen human milk, pasteurized human milk, and pasteurized cow's milk all
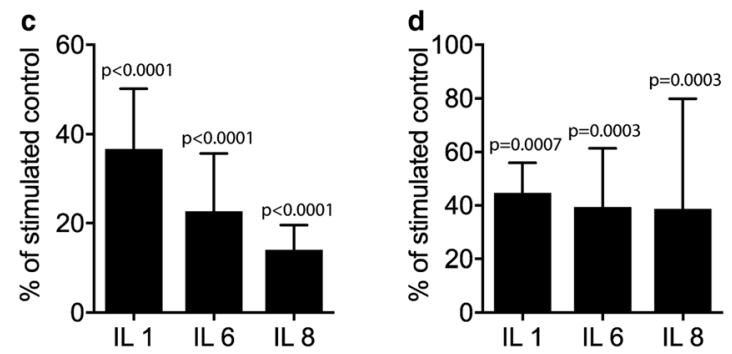

whey with and without IL1 and TNF $\alpha$. Data indicate a percentage of gene expression changes compared to control fibroblasts treated with inflammatory factors. $P$ values are indicated in the graphs 


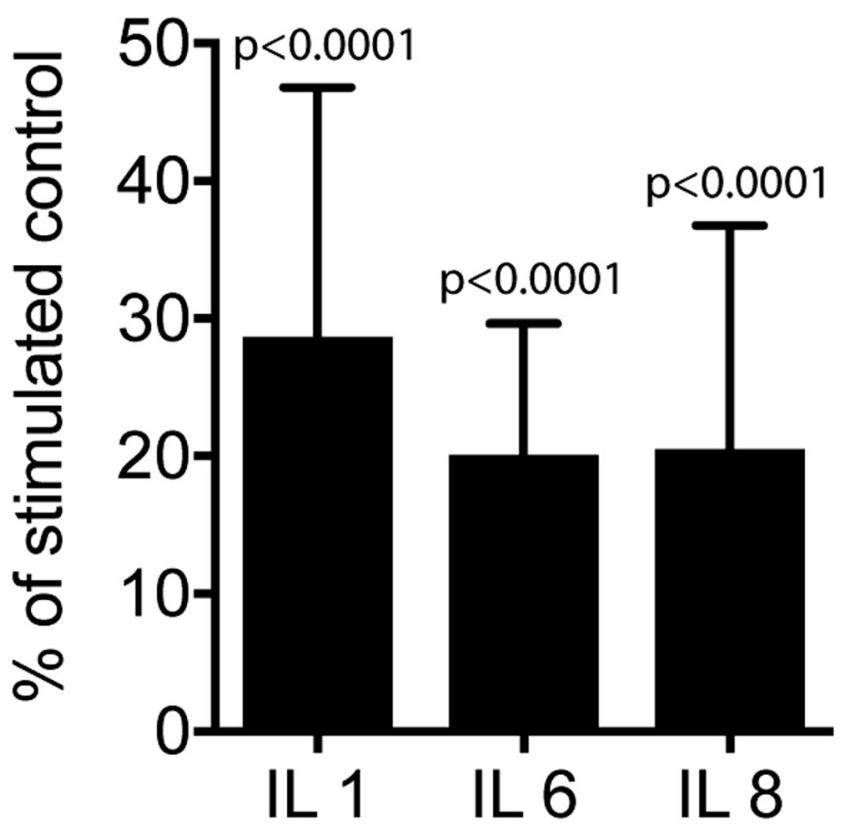

Fig. 3 Sprayed dried milk reduces IL1-TNF $\alpha$-induced inflammation in gingival fibroblasts. Gingival fibroblasts were exposed to aqueous fractions of sprayed dried milk with and without IL1 and $\mathrm{TNF} \alpha$. Data indicate a percentage of gene expression changes compared to control fibroblasts treated with inflammatory factors. $P$ values are indicated in the graphs

lowered the inflammatory response of gingival fibroblasts exposed to IL1 and TNF $\alpha$. The reduction in gene expression was at least $40 \%$ in fibroblasts treated with IL1 and TNF $\alpha$ (Fig. 1). Dose-response experiments indicated that even $0.1 \%$ pasteurized human milk has an anti-inflammatory effect on an in vitro model (data not shown). Further support for the reduced inflammatory response comes from immunoassays showing that IL6 and IL8 in the supernatant reduced inflammation when gingival fibroblasts were exposed to $5 \%$ fresh-frozen human milk, pasteurized human milk, and pasteurized cow's milk (Table 1). Together, these findings indicate that milk induces an anti-inflammatory activity in an in vitro setting when gingival fibroblasts are stimulated with IL1 and TNF $\alpha$.

\section{Fermented milk products and powdered milk reduce IL1-TNFa-induced inflammation in gingival fibroblasts}

Aqueous fractions of pooled yoghurt, sour milk, buttermilk, and whey each reduced the inflammatory response of gingival fibroblasts exposed to IL1 and TNF $\alpha$. The decrease in gene expression was at least $50 \%$ of the positive control in gingival fibroblasts (Fig. 2). Moreover, 5\% powdered milk from three independent manufacturers caused a substantial reduction of at least $70 \%$ in the inflammatory response of gingival fibroblasts exposed to IL1 and TNF $\alpha$ (Fig. 3). Collectively, these data suggest that not only fermented milk products but also powdered milk maintain the anti-inflammatory activity of milk in a model using gingival fibroblasts.

\section{Human milk and cow's milk suppress IL1-TNFa-induced inflammation in human epithelial cells}

When the human oral epithelial cell line HSC2 was exposed to IL1 and TNF $\alpha$, fresh-frozen human milk, pasteurized human milk, and pasteurized cow's milk once again lowered the inflammatory response. The reduction in gene expression was at least $40 \%$ in the respective positive control fibroblasts treated with IL1 and TNF $\alpha$ (Fig. 4). Thus, the aqueous fractions of fresh-frozen

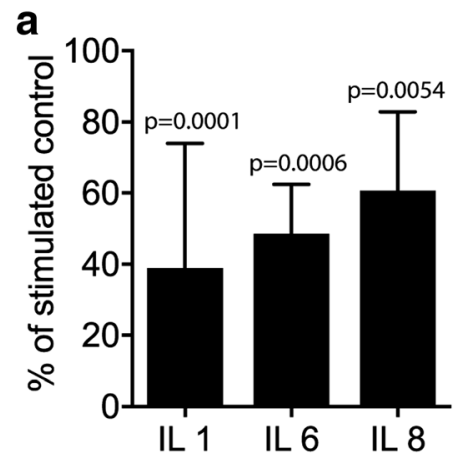

Fig. 4 Human and cow's milk suppress IL1-TNF $\alpha$-induced inflammation in human epithelial cells. HSC2 human epithelial cells were exposed to a fresh-frozen human milk, b pasteurized human milk, and $\mathbf{c}$ pasteurized
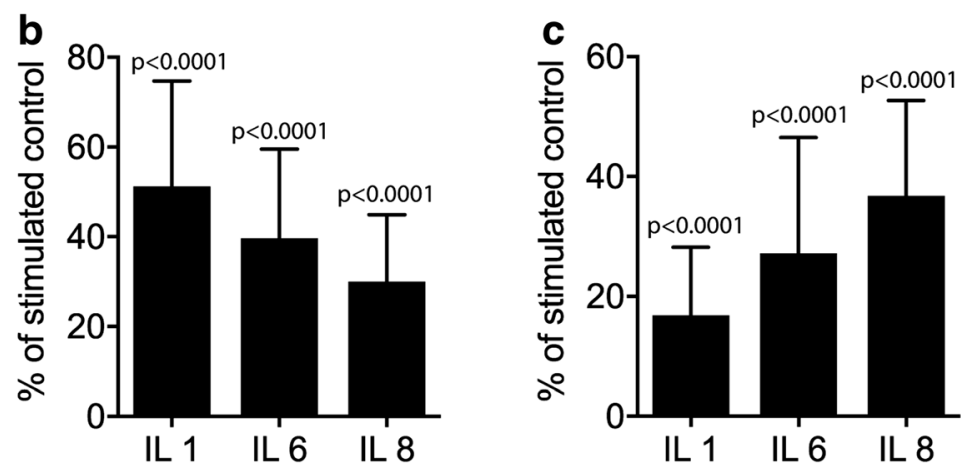

cow's milk with and without IL1 and TNF $\alpha$. Data indicate a percentage of gene expression changes compared to control fibroblasts treated with inflammatory factors. $P$ values are indicated in the graphs 

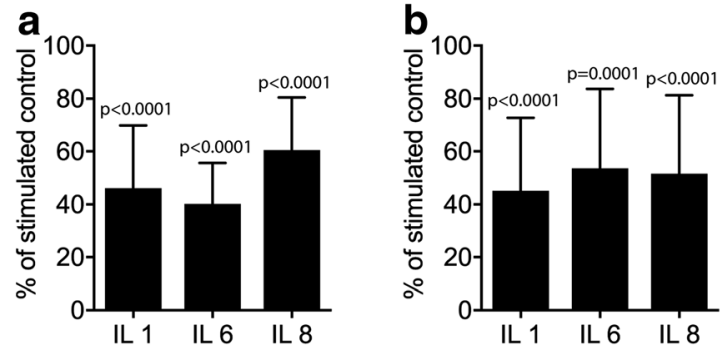

Fig. 5 Fermented milk products reduce IL $1-\mathrm{TNF} \alpha$-induced inflammation in human epithelial cells. HSC2 human epithelial cells were exposed to aqueous fractions of a pooled yoghurt, b sour milk, c
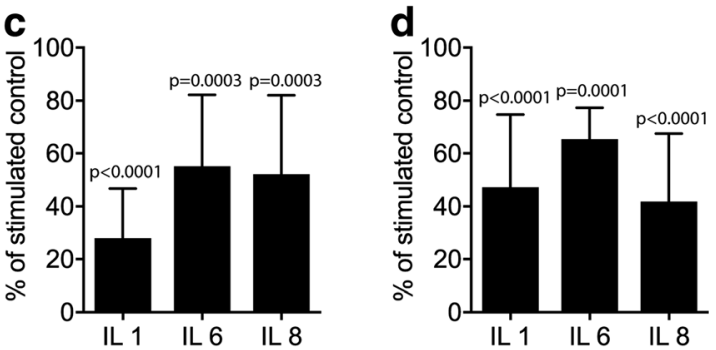

buttermilk, and $\mathbf{d}$ whey with and without IL1 and TNF $\alpha$. Data indicate a percent of gene expression changes compared to control fibroblasts treated with inflammatory factors. $P$ values are indicated in the graphs human milk, pasteurized human milk, and pasteurized cow's milk also hold an anti-inflammatory potential in oral epithelial cells.

\section{Fermented milk products and powdered milk reduce IL1-TNFa-induced inflammation in human epithelial cells}

As observed with gingival fibroblasts, a 5\% aqueous fraction of pooled yoghurt, sour milk, buttermilk, and whey reduced the inflammatory response of the human epithelial cell line HSC2 exposed to IL1 and TNF $\alpha$. The

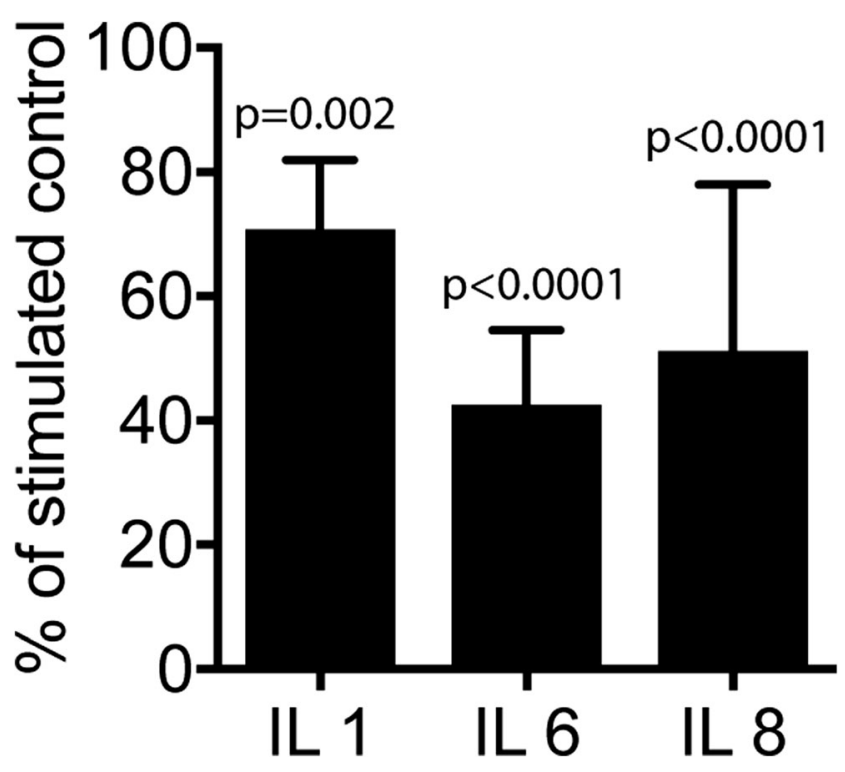

Fig. 6 Powdered milk products reduce IL $1-T N F \alpha$-induced inflammation in human epithelial cells. HSC2 human epithelial cells were exposed to aqueous fractions of powdered milk with and without IL1 and TNF $\alpha$. Data indicate a percent of gene expression changes compared to control fibroblasts treated with inflammatory factors. $P$ values are indicated in the graphs reduction in expression of inflammatory genes was at least $30 \%$ in the HSC2 cells treated with IL 1 and TNF $\alpha$ (Fig. 5). Likewise, powdered milk from three companies caused a significant decrease of at least $30 \%$ in the inflammatory response of HSC2 cells exposed to IL1 and TNF $\alpha$ (Fig. 6). These observations suggest that fermented milk products as well as powdered milk have an anti-inflammatory activity in vitro when using human epithelial cells (Table 2).

\section{Discussion}

Oral mucositis is a critical issue in patients exposed to radiation [19] and/or chemotherapy [20], and in those with chronic inflammatory disorders such as Crohn's disease [21], periodontitis, and peri-implantitis. Today's anti-inflammatory strategies include antibiotics, as well as oral mouth rinses supplemented with chlorhexidine [22] and other pharmacological compounds [23]. These potent therapies, however, have side effects and should be restricted to a limited time period [24]. Consequently, there is a growing demand for anti-inflammatory strategies to complement the range of traditional pharmacological therapies. These are based on natural components such as propolis [25], green tea [26], and aloe vera [27]. The possible anti-inflammatory effect of milk and related products for the oral cavity has not been considered so far, even though there is strong evidence that milk can reduce inflammation of the intestine [1, 2]. The main finding of the present study was that pasteurized human milk and pasteurized cow's milk, as well as also yoghurt, buttermilk, sour milk, whey, and dry milk reduce the inflammatory response of gingival fibroblasts and oral epithelial cells exposed to IL1 and TNF $\alpha$.

Questions arising are related to the ranking of the tested compounds. In this way, a clinician would have 
Table 2 Human milk and cow's milk suppress IL1-TNF $\alpha$-induced IL8 production in gingival fibroblasts. Gingival fibroblasts were exposed to fresh-frozen human milk, pasteurized human milk, and pasteurized cow's milk with and without IL1 and TNF $\alpha$. No statistical analysis was performed. $M M$ human milk, $H M M$ pasteurized human milk, $C M$ pasteurized cow's milk

\begin{tabular}{llrlclll}
\hline wo & IL1 + TNF & MM & MM + IL1 + TNF & HMM & HMM + IL1 + TNF & CM & CM + IL1 + TNF \\
\hline 2 & 800 & 10 & - & 15 & 654 & 5 & 337 \\
3 & 455 & 5 & 404 & 4 & 284 & 2 & 358 \\
\hline
\end{tabular}

a better idea which dairy products were most effective at lowering inflammation The present study, however, was exploratory, meaning that it was not our intension to compare the anti-inflammatory activity of the various preparations; hence, the study is underpowered for this purpose and the variation between the experiments was rather high, likely because of the variation caused by the primary cells and variations between the different batches within one group. Nevertheless, we did a nonparametric comparison of all seven groups and failed to reach the level of significance. Hence, it requires a more controlled setting to determine possible differences in the antiinflammatory activity of the groups investigated.

If we relate these findings to those of other researchers, the results are consistent with observations in different in vitro systems. For example, pre-term human milk suppresses TNF-induced inflammation in intestinal epithelial cells [4]. All other in vitro studies focus on fractions of milk such as hydrolysate to reduce the inflammatory response of TNF $\alpha$-challenged colon cancer cells and LPS-challenged porcine colonic explants [5]. Moreover, whey protein hydrolysates decrease IL8 secretion in LPS-stimulated respiratory epithelial cells [6]. Thus, there is moderate knowledge of the in vitro antiinflammatory activity of milk and related products, even though there is strong evidence from pre-clinical research and clinical studies that milk prevents enterocolitis [1]. The present in vitro research therefore advances current knowledge based on intestinal epithelial cells, adding further support for the anti-inflammatory activity of milk and related products in oral gingival fibroblasts and a human oral epithelial cell line.

The underlying molecular mechanism responsible for the anti-inflammatory effect of milk and its respective products remains open. Considering that casein and whey hydrolysates display an anti-inflammatory effect on colon and respiratory epithelial cells $[5,6]$, together with our findings based on fermented milk products and even powdered milk (the latter being heated up to $160^{\circ} \mathrm{C}$ ) [11], it is likely that a milk component which resists heating and fermentation is responsible for the anti-inflammatory activity in the various cell types. Soluble TNF $\alpha$ receptors IL1Ra neutralizing the bioactivity of the respective cytokines [28, 29] are present in milk but are presumably not that heat stable to exert the antiinflammatory activity of powdered milk.

Human milk oligosaccharides have an anti-inflammatory effect and are resistant to pasteurization and freeze-drying [30]. They are highly abundant in milk besides lactose, fat, and proteins. There is an existing hypothesis that milk oligosaccharides reduce the risk of necrotizing enterocolitis in premature infants [31, 32]. Moreover, milk oligosaccharides can suppress inflammation in colonic epithelial cells [33] and trinitrobenzenesulfonic acid-induced colitis in rats [34]. Milk oligosaccharides also reduce E. coli-induced interleukin IL8 release by intestinal epithelial cells [35]. It is likely that milk and its respective products exert their anti-inflammatory effect possibly independent of the target cell for IL1 and TNF $\alpha$. What also remains to be clarified in future research is whether milk neutralizes IL1 and TNF $\alpha$, and consequently prevents the binding to the respective receptors, or if it activates the anti-inflammatory mechanism that suppresses activation of the inflammosome [36].

The clinical relevance of the present data remains at the level of speculation. Even though in vitro, milk, fermented milk products, and powdered milk possess a potent antiinflammatory effect, as to whether this observation can be applied to patients suffering from oral mucositis is questionable. Epidemiological research into the association between the intake of yoghurt and the incidence of periodontitis, in a nationally representative sample of Korean adults, conflicts with this proposition [37]. Recent systematic reviews on the protective effect of breastfeeding with respect to malocclusion and caries raise a possible role of milk in oral health, but not with a focus on inflammation [38]. Again, the pre-clinical and the clinical data supporting milk in preventing enterocolitis only serve as a basis for a hypothesis on the possible antiinflammatory activity of milk in the oral cavity.

Acknowledgements The authors thank Gabriele Haar for technical assistance.

Funding Information Open access funding provided by Medical University of Vienna. The work was partially financially supported by the Department of Oral Biology, Medical University of Vienna, and a grant from the Osteology Foundation. Layla Panahipour and Reinhard 
Gruber were financially supported by a grant from the Osteology Foundation.

\section{Compliance with ethical standards}

Conflict of interest The authors declare that they have no conflict of interest.

Ethical approval Mother's milk was prepared in daily totals for premature babies and delivered to the feeding stations; leftover milk was used for this study. Ethical Committee of the Medical University of Vienna Nr. 1021/2017. Human gingival fibroblasts were prepared from explant cultures of three independent donors, EK Nr. 631/2007.

Informed consent Informed consent was obtained from all individual participants included in the study.

Open Access This article is distributed under the terms of the Creative Commons Attribution 4.0 International License (http:// creativecommons.org/licenses/by/4.0/), which permits unrestricted use, distribution, and reproduction in any medium, provided you give appropriate credit to the original author(s) and the source, provide a link to the Creative Commons license, and indicate if changes were made.

\section{References}

1. Sisk PM, Lovelady CA, Dillard RG, Gruber KJ, O'Shea TM (2007) Early human milk feeding is associated with a lower risk of necrotizing enterocolitis in very low birth weight infants. J Perinatol 27: 428-433. https://doi.org/10.1038/sj.jp. 7211758

2. Namachivayam K, Blanco CL, Frost BL, Reeves AA, Jagadeeswaran R, MohanKumar K, Safarulla A, Mandal P, Garzon SA, Raj JU, Maheshwari A (2013) Preterm human milk contains a large pool of latent TGF-beta, which can be activated by exogenous neuraminidase. Am J Physiol Gastrointest Liver Physiol 304:G1055-G1065. https://doi. org/10.1152/ajpgi.00039.2013

3. Ozawa T, Miyata M, Nishimura M, Ando T, Ouyang Y, Ohba T, Shimokawa N, Ohnuma Y, Katoh R, Ogawa H, Nakao A (2009) Transforming growth factor-beta activity in commercially available pasteurized cow milk provides protection against inflammation in mice. J Nutr 139:69-75. https://doi.org/10.3945/jn.108.092528

4. Chen Y, Patel A, Meier PP, Fantuzzi G (2018) Digested early preterm human Milk suppresses tumor necrosis factor-induced inflammation and cytotoxicity in intestinal epithelial cells. J Pediatr Gastroenterol Nutr 66:e153-e157. https://doi.org/10. 1097/MPG.0000000000001932

5. Mukhopadhya A, Noronha N, Bahar B, Ryan MT, Murray BA, Kelly PM, O'Loughlin IB, O’Doherty JV, Sweeney T (2014) Anti-inflammatory effects of a casein hydrolysate and its peptideenriched fractions on TNFalpha-challenged Caco-2 cells and LPSchallenged porcine colonic explants. Food Sci Nutr 2:712-723. https://doi.org/10.1002/fsn3.153

6. Iskandar MM, Dauletbaev N, Kubow S, Mawji N, Lands LC (2013) Whey protein hydrolysates decrease IL-8 secretion in lipopolysaccharide (LPS)-stimulated respiratory epithelial cells by affecting LPS binding to Toll-like receptor 4. Br J Nutr 110:58 68. https://doi.org/10.1017/S0007114512004655

7. Pepe G, Tenore GC, Conte C, Russo M, Manfra M, Campiglia P (2013) Susceptibility to denaturation of caseins in milk samples for improving protein conformational study and their identification. Nat Prod Res 27:1508-1512. https:// doi.org/10.1080/14786419.2012.724411

8. Ranieri ML, Huck JR, Sonnen M, Barbano DM, Boor KJ (2009) High temperature, short time pasteurization temperatures inversely affect bacterial numbers during refrigerated storage of pasteurized fluid milk. J Dairy Sci 92:4823-4832. https://doi.org/10.3168/jds.2009-2144

9. Jablonski JE, Jackson LS (2008) Stability of picrotoxin during yogurt manufacture and storage. J Food Sci 73:T121-T128. https:// doi.org/10.1111/j.1750-3841.2008.00911.x

10. Bonczar G, Walczycka M, Duda I (2016) The changes of proteins fractions shares in milk and fermented milk drinks. Acta Sci Pol Technol Aliment 15:379-389. https://doi.org/10. 17306/J.AFS.2016.4.36

11. Park CW, Stout MA, Drake M (2016) The effect of spraydrying parameters on the flavor of nonfat dry milk and milk protein concentrate 70. J Dairy Sci 99:9598-9610. https://doi. org/10.3168/jds.2016-11692

12. Hsieh JF, Pan PH (2012) Proteomic profiling of the coagulation of milk proteins induced by chymosin. J Agric Food Chem 60:20392045. https://doi.org/10.1021/jf204582g

13. Xiao K, Jiao L, Cao S, Song Z, Hu C, Han X (2016) Whey protein concentrate enhances intestinal integrity and influences transforming growth factor-betal and mitogen-activated protein kinase signalling pathways in piglets after lipopolysaccharide challenge. Br J Nutr 115:984-993. https://doi.org/10.1017/ S0007114515005085

14. Gobbato N, Rachid M, Perdigon G (2008) Anti-inflammatory effect of yoghurt in an experimental inflammatory bowel disease in mouse. J Dairy Res 75:497-504. https://doi.org/10.1017/ S0022029908003579

15. Lorea Baroja M, Kirjavainen PV, Hekmat S, Reid G (2007) Antiinflammatory effects of probiotic yogurt in inflammatory bowel disease patients. Clin Exp Immunol 149:470-479. https://doi.org/ 10.1111/j.1365-2249.2007.03434.x

16. Terayama Y, Matsuura T, Uchida M, Narama I, Ozaki K (2016) Probiotic (yogurt) containing Lactobacillus gasseri OLL2716 is effective for preventing Candida albicans-induced mucosal inflammation and proliferation in the forestomach of diabetic rats. Histol Histopathol 31:689-697. https://doi.org/10.14670/HH-11-710

17. Cvikl B, Lussi A, Moritz A, Sculean A, Gruber R (2015) Sterile-filtered saliva is a strong inducer of IL-6 and IL-8 in oral fibroblasts. Clin Oral Investig 19:385-399. https://doi.org/10.1007/s00784-014-1232-3

18. Hosokawa Y, Hosokawa I, Ozaki K, Matsuo T (2017) IL-27 modulates chemokine production in TNF-alpha -stimulated human Oral epithelial cells. Cell Physiol Biochem 43:1198-1206. https://doi. org/10.1159/000481760

19. Maria OM, Eliopoulos N, Muanza T (2017) Radiationinduced oral mucositis. Front Oncol 7:89. https://doi.org/10. 3389/fonc.2017.00089

20. Lalla RV, Saunders DP, Peterson DE (2014) Chemotherapy or radiation-induced oral mucositis. Dent Clin N Am 58:341-349. https://doi.org/10.1016/j.cden.2013.12.005

21. Harty S, Fleming P, Rowland M, Crushell E, McDermott M, Drumm B, Bourke B (2005) A prospective study of the oral manifestations of Crohn's disease. Clin Gastroenterol Hepatol 3:886-891

22. James P, Worthington HV, Parnell C, Harding M, Lamont T, Cheung A, Whelton H, Riley P (2017) Chlorhexidine mouthrinse as an 
adjunctive treatment for gingival health. Cochrane Database Syst Rev 3:CD008676. https://doi.org/10.1002/14651858.CD008676.pub2

23. Muller HD, Eick S, Moritz A, Lussi A, Gruber R (2017) Cytotoxicity and antimicrobial activity of oral rinses in vitro. Biomed Res Int 2017: 4019723-4019729. https://doi.org/10.1155/2017/4019723

24. Karpinski TM, Szkaradkiewicz AK (2015) Chlorhexidinepharmaco-biological activity and application. Eur Rev Med Pharmacol Sci 19:1321-1326

25. Khurshid Z, Naseem M, Zafar MS, Najeeb S, Zohaib S (2017) Propolis: a natural biomaterial for dental and oral healthcare. J Dent Res Dent Clin Dent Prospects 11:265-274. https://doi.org/ 10.15171/joddd.2017.046

26. Mathur A, Gopalakrishnan D, Mehta V, Rizwan SA, Shetiya SH, Bagwe S (2018) Efficacy of green tea-based mouthwashes on dental plaque and gingival inflammation: a systematic review and meta-analysis. Indian J Dent Res 29: 225-232. https://doi.org/10.4103/ijdr.IJDR_493_17

27. Dhingra K (2014) Aloe vera herbal dentifrices for plaque and gingivitis control: a systematic review. Oral Dis 20:254-267. https:// doi.org/10.1111/odi.12113

28. Buescher ES, McWilliams-Koeppen P (1998) Soluble tumor necrosis factor-alpha (TNF-alpha) receptors in human colostrum and milk bind to TNF-alpha and neutralize TNF-alpha bioactivity. Pediatr Res 44:37-42. https://doi.org/10.1203/00006450199807000-00006

29. Buescher ES, Malinowska I (1996) Soluble receptors and cytokine antagonists in human milk. Pediatr Res 40:839-844. https://doi.org/ 10.1203/00006450-199612000-00011

30. Hahn WH, Kim J, Song S, Park S, Kang NM (2017) The human milk oligosaccharides are not affected by pasteurization and freezedrying. J Matern Fetal Neonatal Med:1-7. https://doi.org/10.1080/ 14767058.2017.1397122

31. Caplan MS (2017) Paediatrics: are human milk oligosaccharides the magic bullet for necrotizing enterocolitis? Nat Rev
Gastroenterol Hepatol 14:394-395. https://doi.org/10.1038/ nrgastro.2017.65

32. Autran CA, Kellman BP, Kim JH, Asztalos E, Blood AB, Spence ECH, Patel AL, Hou J, Lewis NE, Bode L (2018) Human milk oligosaccharide composition predicts risk of necrotising enterocolitis in preterm infants. Gut 67:1064-1070. https://doi.org/10.1136/ gutjnl-2016-312819

33. Newburg DS, Ko JS, Leone S, Nanthakumar NN (2016) Human milk oligosaccharides and synthetic galactosyloligosaccharides contain 3'-, 4-, and 6'-galactosyllactose and attenuate inflammation in human T84, NCM-460, and H4 cells and intestinal tissue ex vivo. J Nutr 146:358-367. https://doi.org/10.3945/jn.115.220749

34. Daddaoua A, Puerta V, Requena P, Martinez-Ferez A, Guadix E, de Medina FS, Zarzuelo A, Suarez MD, Boza JJ, Martinez-Augustin O (2006) Goat milk oligosaccharides are anti-inflammatory in rats with hapten-induced colitis. J Nutr 136:672-676. https://doi.org/ 10.1093/jn/136.3.672

35. He Y, Liu S, Kling DE, Leone S, Lawlor NT, Huang Y, Feinberg SB, Hill DR, Newburg DS (2016) The human milk oligosaccharide 2 '-fucosyllactose modulates CD14 expression in human enterocytes, thereby attenuating LPS-induced inflammation. Gut 65:33-46. https://doi.org/10.1136/gutjnl-2014-307544

36. Broz P, Dixit VM (2016) Inflammasomes: mechanism of assembly, regulation and signalling. Nat Rev Immunol 16:407-420. https:// doi.org/10.1038/nri.2016.58

37. Kim HS, Kim YY, Oh JK, Bae KH (2017) Is yogurt intake associated with periodontitis due to calcium? PLoS One 12:e187258. https://doi.org/10.1371/journal.pone.0187258

38. Peres KG, Chaffee BW, Feldens CA, Flores-Mir C, Moynihan P, Rugg-Gunn A (2018) Breastfeeding and oral health: evidence and methodological challenges. J Dent Res 97:251-258. https://doi.org/ $10.1177 / 0022034517738925$ 